\title{
Evaluating demand responsive transit services using a density- based trip rate metric
}

\author{
Benjamin Kaufman \\ Griffith University \\ benjamin.kaufman@griffithuni.edu.au \\ Matthew Burke \\ Griffith University \\ m.burke@griffith.edu.au
}

\author{
Abraham Leung \\ Griffith University \\ abraham.leung@griffith.edu.au
}

\begin{abstract}
Demand responsive transit (DRT) is attracting increased attention as a means to provide public transit to low-density populations. This research aims to provide a suite of evaluation metrics with low data requirement and widespread availability, so that operators, funders, regulators, and practitioners can better evaluate the performance of DRT services. Trip numbers can be divided by a number of available variables (period, trip length, population, and density) to create a number of derived metrics. By applying these variables across three different DRT service areas in Logan City, Australia, where other key factors are held constant, one can see how different formulations lead to very different readings of DRT system performance. The results confirm the dilemma of cost efficiency versus equity in service provision in low-density environments. This paper also highlights current data limitations and calls for better data collection to facilitate the development of new evaluation methods for DRT services and a new composite metric that can be used for inter-service comparison.
\end{abstract}

\section{Article history:}

Received: May 13, 2020

Received in revised form:

January 28, 2021

Accepted: February 1, 2021

Available online: April 14, 2021

\section{Introduction}

Low density suburbs and rural areas are challenging and costly for public transit operators to serve (White, 2016). Demand Responsive Transit (DRT) is a shared form of public transit where vehicles adjust their routes based on demand. It contrasts with conventional transit that follows fixed routes and timetables, hereafter referred to as fixed route transit (FRT). DRT has been touted as an effective solution for providing public transit in low density areas (Ryley, Stanley, Enoch, Zanni, \& Quddus, 2014). The equity impacts of FRT has been demonstrated, but for DRT this concept is less well documented (Walker, 2011). Though interest in and real-world application of DRT systems are growing, there are limited methods to evaluate system performance (Ho et al., 2018; Mulley \& Nelson, 2009; Perera, Ho, \& Hensher, 2019). There are no normative design rules for DRT systems and as such there are no standard evaluation or planning techniques for system comparison (Papanikolaoua, Basbasa, Mintsisa, \& Taxiltaris, 2017, p. 394). What may be perceived as success or failure in a particular DRT system differ when one completes a quantitative evaluation of performance and service quality (Enoch, Potter,

Copyright 2021 Benjamin Kaufman, Abraham Leung \& Matthew Burke

http://dx.doi.org/10.5198/jtlu.2021.1796

ISSN: 1938-7849 | Licensed under the Creative Commons Attribution - Noncommercial License 4.0

The Journal of Transport and Land Use is the official journal of the World Society for Transport and Land Use (WSTLUR) and is published and sponsored by the University of Minnesota Center for Transportation Studies. 
Parkhurst, \& Smith, 2006). DRT systems need comparable, consistent metrics for service evaluation. But what should this look like?

This research proposes a novel yet simple method for DRT operators, funders, regulators, and practitioners to evaluate the performance of services in varying spatial contexts using commonly available data inputs. An integrated transport and land-use approach is adopted and applied to the Logan DRT Trial in Brisbane, Australia. Three DRT service regions with varying spatial contexts are analyzed. Trip rate per area, or demand density is more suitable for estimating cost per service, while trip rates based on population density are more suitable for evaluating overall service equity. Defining the goals of an individual DRT service therefore becomes more important in deciding success factors, rather than the common practice of simply counting passenger trip rates. The paper concludes with a set of recommendations for future data collection and possible analytical approaches if high resolution temporal and spatial DRT demand and supply data is available.

\section{Background}

DRT services vary in their designation of stops, some acting similar to a bus but deviating from their route to pick up customers; others resemble ride-hailing companies or taxis, responding solely to ride requests and operating within broader service regions. In an effort to understand the many different forms of DRT, descriptive studies have classified four main use cases: i) feeder; ii) network; iii) destination; and iv) replacement DRT. Each use case has associated operational and design characteristics (Enoch, Potter, Parkhurst, \& Smith, 2004, p. 37). These use cases have allowed DRT to increase public transit provision in low density areas and to aid those who have decreased personal mobility, improving access to opportunities and transport equity (Nelson \& Phonphitakchai, 2012). There are many modifications to and combinations of these use cases, encompassing variations in routing and service areas (Brake, Mulley, \& Nelson, 2006, p. 15). The service that is the focus of this research falls under both feeder and network classifications, providing access to trunk public transit and to local amenities such as grocery stores and health care.

\subsection{Means to promote equity and accessibility through transport}

Land uses matter as transport planning's emphasis is shifting away from providing increased mobility and towards providing access to opportunities/land uses (Litman, 2013). When transport planning focused on improving mobility, minimizing motor vehicle travel time and increasing travel speeds for individuals were primary concerns for planners (Behbahani, Nazari, Jafari Kang, \& Litman, 2018, p. 1). Mobility problems are often analyzed through the lenses of levels of service (congestion), vehicle miles travelled, cost per mile, and travel speeds. In a mobility paradigm, the faster one can move from an origin to a destination, the better. Limited attention was given to those who could not or would not attempt to achieve this high level of mobility.

While mobility emphasizes movement, accessibility is defined as "people's ability to reach services and activities" (Behbahani et al., 2018, p. 7) or as "the potential of opportunities for interaction" (Hansen, 1959, p. 73). Those who are less mobile in a car-centric city-region, such as individuals without cars, seniors, young people, those of lower socioeconomic status, or the mobility impaired, have limited access to opportunities such as workplaces and public services and are less able to compete with their faster automobile counterparts (Social Exclusion Unit, 2003, p. 9). This is particularly detrimental when an individual is situated in an area with inadequate public transport provision (Lucas, 2012). People who are less wealthy, skilled, healthy, or able-bodied are less able to travel large distances than their more 
privileged counterparts (Hine, 2011; Lucas, 2012). Focusing on accessibility gives greater importance to an individual's ability to travel and promotes equity (Lucas, Phillips, Mulley, \& Ma, 2018, p. 622). Martens (2006, p. 3) notes that most public policies implement equity considerations as "instruments to address the special needs of weak population groups", rather than as a foundation of planning. DRT originated as a means of reactively providing transport to those who were physically unable to access FRT (Oxley, 2007). Now it is increasingly being provided as a way to address equity of access across service areas, especially in suburban and rural locations with a paucity of public transit.

Equity can be conceptualized in two forms: horizontal and vertical equity. The former seeks to promote equal treatment of social groups, avoiding favoritism and uplifting society as a whole. Vertical equity seeks to target those groups that are disadvantaged, promoting benefits for those who may need aid and reducing the gap between advantaged and disadvantaged groups (Rawls, 1971; Sen, 2009). Gini Coefficients are often used to evaluate vertical equity across a population as they allow for quantification of wealth distribution across a selected population, along a scale from perfect to absolutely imperfect equality (Bertolaccini \& Lownes, 2013). However, expansion of these metrics is needed when specifically evaluating DRT services. Exploring how DRT services are evaluated and the benefits and limitations of the main existing metrics helps to explain why improvement is needed.

\subsection{Transport service evaluation}

Measurement of a transit system's performance is necessary to benchmark provision and demonstrate increase in value for customers compared with past services (Eboli \& Mazzulla, 2012). Particular importance must be paid to the performance metrics used in evaluations, as they ultimately determine how success is measured and what aspects of service provision are improved.

Approaches and methods used for evaluating other public transit modes can aid in the evaluation of DRT services. This includes common metrics such as subsidy per capita or subsidy per trip - a useful indicator of cost vs. benefit for any such service. However, more nuanced insights are needed when considering DRT services in low-density environments. Planning for DRT is quite different from FRT bus planning and demands its own methods for evaluation of services (Alonso-González, Liu, Cats, Van Oort, \& Hoogendoorn, 2018; Ferreira, Charles, \& Tether, 2007; Papanikolaoua et al., 2017; Reinhardt, Clausen, \& Pisinger, 2013). One clear difference in service design is that many DRT services are based on regional coverage, and are not tied directly to individual stops as with FRT. When planning for DRT, as with most transit services, the coverage area of the service region, and its population, should generally be optimized (Brake, Nelson, \& Wright, 2004). Demand density (trips/hour/area) is a common metric to estimate the level of DRT demand in an area (Heramb, Sen, \& Soot, 1979; Holoszyc, 1979; Kim, Schonfeld, \& Kim, 2018; Li \& Quadrifoglio, 2010). However, such an approach takes service region as the denominator and may favor smaller areas while penalizing larger less-dense areas, regardless of sociodemographic need. Cost-based metrics are also widely used, which include passenger trips per revenue hour, operating cost per revenue hour, and operating cost per passenger trip (National Academy of Sciences, 2008). However, cost metrics are usually calculated at system-wide levels, which have limitations if trying to compare disaggregate service regions. Again, cost metrics are also blind to most vertical and horizontal equity considerations. As DRT services require advanced technologies for routing, costs for scheduling and dispatching must be captured in any operating cost metric, though this is resolvable. But cost and service goals do not always align for operators and transport agencies, and contextual settings must be accounted for when comparing individual services (Narayan, Cats, van Oort, \& Hoogendoorn, 2020).

Passenger trips per revenue hour is often the most important measure of DRT performance, demonstrating overall system effectiveness. Risks of relying on this metric include network redundancy be- 
tween transit modes, as DRT moves into dense areas better served by trunk transit services, and the lack of focus on who is making those trips. With DRT services, fleet sizing plays a large role in both determining costs and controlling demand, alongside guidelines and logistics for pooling of rides (Narayan et al., 2020).

Operating cost per revenue hour can be useful when comparing systems that are performing similarly on other metrics. A majority of DRT costs in the industrialized world tend to be labor and employee benefits, which "account for up to 70 to $80 \%$ of total operating costs, with the majority of employees working in vehicle operations" (National Academy of Sciences, 2008). This represents a major opportunity for cost savings as autonomous vehicles are developed and integrated into transit fleet deployment. However, this metric fails to consider service levels, making it very difficult to use in isolation (for example, operating costs may be very low due to a lack of service provided).

Operating cost per passenger trip is commonly used to compare DRT services to other forms of public transit. However, this metric inherently leaves DRT at a distinct disadvantage. DRT services are, by their nature, designed for low passenger loads and longer trip distances and tend to have higher costs by this measure. The metric is useful though to help identify areas for implementation of DRT services instead of low performing bus routes, maintaining levels of access whilst achieving cost savings.

Not necessarily related to cost, on-time performance is a key determinant of the quality of DRT service from the consumer's point of view. As DRT services often connect riders to FRT services with modest or low service frequencies, and to medical appointments, many DRT trips are highly time sensitive. For round-trip bookings, late arrivals or premature departures may result in passengers being unable to accomplish their intended trip purposes.

Often these varied metrics pull in different directions. For example, maximizing trips or lowering costs may hinder on-time performance. Increasing passenger trips per revenue hour by increasing service levels will increase operational costs. Each of these metrics represent outcomes of service design and fail to encapsulate many of the causes of performance, one of which is land use in which the system operates. The need for a set of metrics that measure all aspects of a DRT system's desired performance is clear (Morse, Trompet, Barron, \& Graham, 2017; National Academy of Sciences, 2008). To allow for comparison of services, the field needs an improved approach incorporating measures that account for not just DRT service outcomes, but also factors in land use and equity attributes. New metrics seem necessary.

\section{Approach and methods}

Analyses of DRT performance should be based on both DRT system use and locational context, with specialized DRT applications especially dependent on context (Zheng, Li, \& Qiu, 2018). In this paper an integrated transport and land-use approach was selected to explore methods for DRT service comparison (Te Brömmelstroet \& Bertolini, 2009). This approach was chosen due to the relationship between DRT performance and the distribution of the populations it serves. A series of metrics with inputs of population density (an important measure of land-use intensity and urban form) and trip rates is developed. The method is intended to be simple and reproducible to allow for both service evaluation and comparison to other services, and to start to account for land use and equity concerns when comparing DRT roll-outs. Cost-based metrics are not considered in this work due to a lack of sufficiently disaggregate cost data. A number of possible variables to evaluate DRT performance are presented here. 


\subsection{Alternative DRT metrics}

The focus in this paper is on metrics that only require data that is generally available for any DRT system, to ensure that any new metrics allow cross-system comparison, and to ensure they are usable by policy-makers and practitioners. These are generally more aggregate metrics as data on costs, passenger trips, and populations just may not be available at disaggregate level. Additional variables were considered but then excluded due to lack of data availability at time of writing, such as equitable coverage impacts, access to employment, vehicle occupancy rate, average cost per trip, and hour of service overlap with FRT systems. These more elaborate options should be a focus for further enquiry and are discussed at length in Section 5.2 at the end of this paper. Eventually the focus was placed upon the aggregated variables service region area, area population, number of trips, and time period.

\subsubsection{Service region area}

DRT offers public transport planners the opportunity to provide many low-density areas with service for the first time, but service regions are often delimited to unique geographies. Sometimes administrative boundaries are used to determine DRT service regions, rather than more logical geographies, due to political requirements. But whatever the boundaries, service region area is important to consider as regions often differ greatly in their size, and it is important to include the total coverage area of transit in comparative analyses (Infrastructure Australia, 2018, p. 26).

\subsubsection{Area population}

Area population is primarily included in order to create the derived metric population density, which is discussed in s3.1.5, below.

\subsubsection{Number of trips}

Trip counts reflect demand being met by the prescribed service design. The number of person trips taken on an individual DRT system is currently the most widely collected and reported piece of publicly available data, with many systems celebrating their "20,000th trip!" or other arbitrary and contextless counting exercises. However, this metric, in isolation, is misleading and fails to account for many service parameters particularly land use. High monthly trip rates may disguise that operations are located in high demand areas or that there is a very large fleet deployed to service a dense region. The public availability of patronage data provides opportunities to compare across different DRT systems, use cases, and locational contexts. The presence of high trip rates could be an indicator that a service could be evaluated as a context for FRT.

In this study, a trip refers to a "person trip", which is defined as "a completed, de-identified, oneway ride within a pre-booked DRT vehicle". Person trips can be shared with other riders (a vehicle transporting three persons would mean three trips). Each person trip may be part of an individual's journey to other destinations. This research focuses only on trips occurred within the DRT service. Further analyses of transfers between DRT services and other modes of transport are not within the scope of this study as such data is not logged in the system.

High person trip numbers, similar to high trips per revenue hour, may be an indicator that a DRT service should actually be met by FRT instead. However, DRT is considered essential for those who are less able to access FRT, such as the mobility impaired. Low person trip numbers may be caused by coverage of very few people or demonstrate that there is low realized demand for DRT service. Similarly, attractors that entice groups to congregate may lead to higher trip numbers. While maximizing the 
number of trips should not be the primary goal of DRT, the number of person trips taken will ultimately distinguish a well-used service area from poor performers.

\subsubsection{Time period}

How often trips occur is also an important dimension in evaluating DRT. Ideally, the performance of individual DRT services should be evaluated at a finer temporal resolution as services vary in performance throughout each day and each week. But for cross-system comparisons, comparisons of averages (by day, week, or month) are appropriate. For the purpose of this study, due both to the availability of public data and to inconsistencies in system performance, monthly averages are used. However, future iterations are not tied to using monthly analyses, especially as services inherently do operate differently during the week and on weekends. These analyses require additional data to perform and are not readily publicly available.

\subsubsection{Derived metrics}

A series of derived metrics are also proposed, as shown in Table 1. These are population density (population/area), \% of pop. who are unique customers, monthly trips per person, demand density, and the population density adjusted trip rate.

Population density and the population density adjusted trip rate are especially important. Transit ridership and population density are generally strongly co-linear. None of the main metrics generally used in cross-service comparisons counter-weigh the effect of higher population density, which limits the potential to understand the influence of other factors and system performance. As such, by not accounting for population density's effects, current evaluation approaches may be suboptimal. By placing population density in the denominator of the population density adjusted trip rate (a novel metric we have not seen used in DRT studies previously), one can at least see what the underlying performance is, when controlling for density's effects. In a similar way, including $\mathrm{km}^{2}$ of service area in the denominator for demand density, allows one to see the trip rate controlling for differences in the size of service area geographies.

Two other important derived metrics are key in understanding how much redundancy there may be when DRT services overlap with FRT routes, as is relatively common. One or more scheduled bus services, albeit with modest frequency, will often traverse a DRT service area. The derived metrics Proportion DRT area within $400 \mathrm{~m}$ of FRT stop and proportion of non-attractor DRT trips located within $400 \mathrm{~m}$ of FRT stop can be calculated relatively easily in GIS software, using what are increasingly publicly available GTSF data on transit stop locations, and streets datasets provided by roads authorities. $400 \mathrm{~m}$ is selected as it approximates a 5-minute walk and is in line with the median walking trip distance to bus stops made in Greater Brisbane in the early 2000s (Burke \& Brown, 2007). 
Table 1. Metrics used in this study

\begin{tabular}{|c|c|c|}
\hline Code / Derived from & Metric & Notes and Sources \\
\hline \multicolumn{3}{|c|}{ “Given” metrics } \\
\hline A & Population (2016) & ABS Census data (2016 used in this study) \\
\hline $\mathrm{B}$ & Area $\left(\mathrm{km}^{2}\right)$ & Based on ABS Census geography in 2016 \\
\hline $\mathrm{C}$ & Unique customers & $\begin{array}{l}\text { Number of unique register users in the Translink } \\
\text { dataset }\end{array}$ \\
\hline $\mathrm{D}$ & Average trip length & $\begin{array}{l}\text { Efficiency measure, based on trip lengths in the } \\
\text { Translink dataset }\end{array}$ \\
\hline $\mathrm{E}$ & Attractors & $\begin{array}{l}\text { Destinations available for booked trips to/from } \\
\text { residential homes within the DRT service region }\end{array}$ \\
\hline $\mathrm{F}$ & System trips per month ${ }^{1}$ & Average monthly ${ }^{1}$ trips across the DRT system \\
\hline \multicolumn{3}{|c|}{ Derived metrics } \\
\hline $\mathrm{G}(\mathrm{A} / \mathrm{B})$ & $\begin{array}{l}\text { Population Density (Population/ } \\
\text { area) }\end{array}$ & Measure of land-use intensity \\
\hline $\mathrm{H}(\mathrm{C} / \mathrm{A})$ & $\begin{array}{l}\% \text { of pop. who are unique } \\
\text { customers }\end{array}$ & $\begin{array}{l}\text { Measure of DRT uptake by number of registered } \\
\text { users from potential resident population }\end{array}$ \\
\hline $\mathrm{I}(\mathrm{F} / \mathrm{A})$ & Monthly ${ }^{1}$ trips per person & $\begin{array}{l}\text { Measure of intensity of DRT use per rider over } \\
\text { time }\end{array}$ \\
\hline $\mathrm{J}(\mathrm{F} / \mathrm{B})$ & Average monthly ${ }^{1}$ trips/area & $\begin{array}{l}\text { Efficiency measure of trip rate per } \mathrm{km}^{2} \text { of service } \\
\text { area (also referred as demand density) }\end{array}$ \\
\hline $\mathrm{K}(\mathrm{F} / \mathrm{G})$ & $\begin{array}{l}\text { Population density adjusted trip } \\
\text { rate }\end{array}$ & Trip rate controlling for the effects of density \\
\hline \multicolumn{3}{|c|}{ FRT spatial coverage metrics } \\
\hline $\begin{array}{l}\mathrm{L}(\% \text { of } \mathrm{B} \text { within } 400 \mathrm{~m} \text { of } \\
\text { FRT stops) }\end{array}$ & $\begin{array}{l}\text { Proportion DRT area within } \\
400 \mathrm{~m} \text { of FRT stop }\end{array}$ & $\begin{array}{l}\text { DRT redundancy measure based on catchment } \\
\text { geographies }\end{array}$ \\
\hline $\begin{array}{l}M(\% \text { of DRT trips located } \\
\text { in K) }\end{array}$ & $\begin{array}{l}\text { Proportion of non-attractor DRT } \\
\text { trips located within } 400 \mathrm{~m} \text { of FRT } \\
\text { stop }\end{array}$ & $\begin{array}{l}\text { DRT redundancy measure based on trip rates } \\
\text { within catchment geographies }\end{array}$ \\
\hline
\end{tabular}

${ }^{1}$ Month is used as the standard time unit of analysis in this paper due to data availability, but daily or weekly averages could also be used if available.

\subsection{The Logan DRT Trial and its service regions}

\subsubsection{Study Area}

The case study covers the Logan DRT Trial that started in October 2017 (Translink, 2019). The Logan local government area is located approximately $20 \mathrm{~km}$ south-east of Brisbane, in the South East Queensland (SEQ) conurbation, and hosts an overall population of 326,000. 70\% of land in Logan is classified as rural or semi-rural (Logan City Council, 2018), which are rapidly becoming suburbanized amidst urban growth and housing shortages in the region. However, non-rural segments of Logan are characterized as low density "dormitory suburbs" with limited employment concentration and overwhelmingly high car use.

The Logan DRT Trial is the result of public campaigning by local community groups and residents in 2017 (Burge, 2017). Three separate DRT service regions were selected for operations, as shown in 
Figure 1 (Translink, 2017). The three service regions have identical operational characteristics in terms of pricing and service, having the same operator and available hours, and the same booking platform. But they differ significantly in terms of area size, population density and FRT provision within their boundaries. The Logan DRT trial service regions are therefore a logical place to look at how the new metrics suggested in this paper perform.

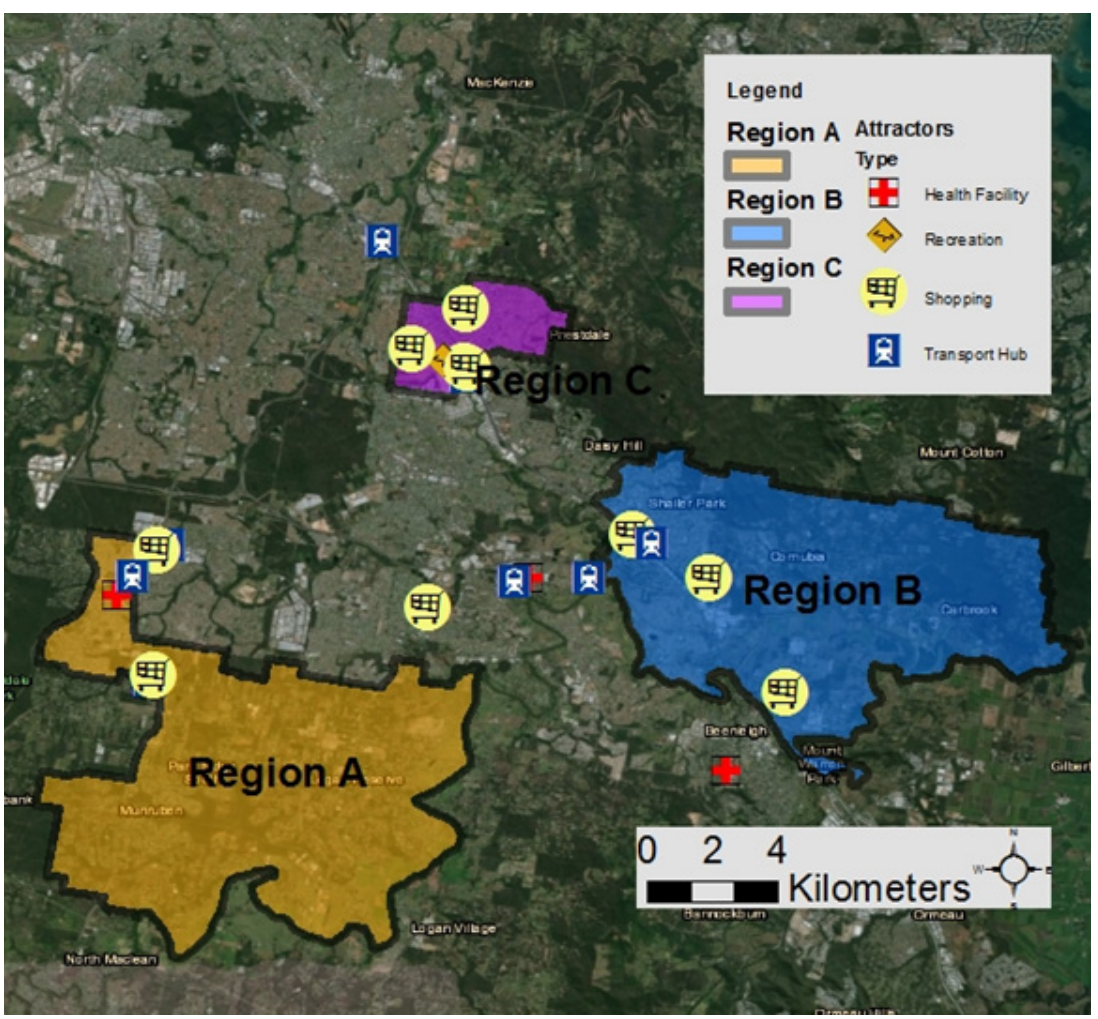

Figure 1. Map of the three Logan DRT Trial regions. Stop locations, known as attractors, are shown.

The Logan DRT is designed to be a connector from residential homes to predetermined stop locations, known as attractors. Attractors include transport hubs (busway/railway stations or park 'n' rides), shopping centers, health (hospitals or clinics) and recreational facilities (e.g., libraries, swimming pools). To limit costs, the service does not offer direct door-to-door services across the region. Such trips generally require an additional mode, such as transferring from DRT to FRT. Each of the three service regions is assigned with designated attractors (see Figure 1, and explained further in subsections 3.2.3 to 3.2.5). This destination type of DRT system generally encourages sharing of rides with other passengers travelling in the same direction at the same time to the same attractors (Stiglic, Agatz, Savelsbergh, \& Gradisar, 2015). A taxi company was awarded the service contract to deliver daily DRT services from Gam to $10 \mathrm{pm}$. Regardless of distance, each DRT ride is charged at \$3AUD ( $-\$ 2 \mathrm{USD})$ per normal adult fare or $\$ 1.50$ AUD ( $\sim \$ 1$ USD) for concession customers (including students, seniors, or job-seekers) with government subsidy covering other costs. The fare price is similar to the local bus fare for a similar distance, but there are no free-transfer discounts if switching from DRT to/from other transit modes. Customers must book each ride at least two hours prior to their trip. The Logan DRT vehicles are identical to the taxi vehicles used by the operator, consisting of either 5-seater sedans or 13-seater vans, the latter with wheelchair access. One of the aims of the Logan DRT trial is to promote horizontal equity by offering a base level of service across the areas served. The service also promotes vertical equity by 
providing specialized services for those who are disadvantaged, such as individuals who need mobility assistance or seek economic help.

By having three regions with a near-identical DRT service, this system provides a "controlled experiment" of how land use and other factors affect ridership allowing one to see if the proposed new metrics perform as hoped.

\subsubsection{Data sources}

The three DRT service regions are described and evaluated using trip data dated from July-September 2019. Anonymized trip and GPS data for each region was provided by Translink, the transit operator under the Queensland Department of Transport and Main roads. Population data was sourced from the 2016 Australian Census at Statistical Area 1 level (the most localized available data) to provide data on geographical and population coverage.

Detailed trip origins/destinations (mostly homes, and not including the designated attractors in each service region) are provided in Figures 2-4. An overview of the three DRT service regions is provided in the following subsections.

\subsubsection{Region A: Mixed suburban and rural}

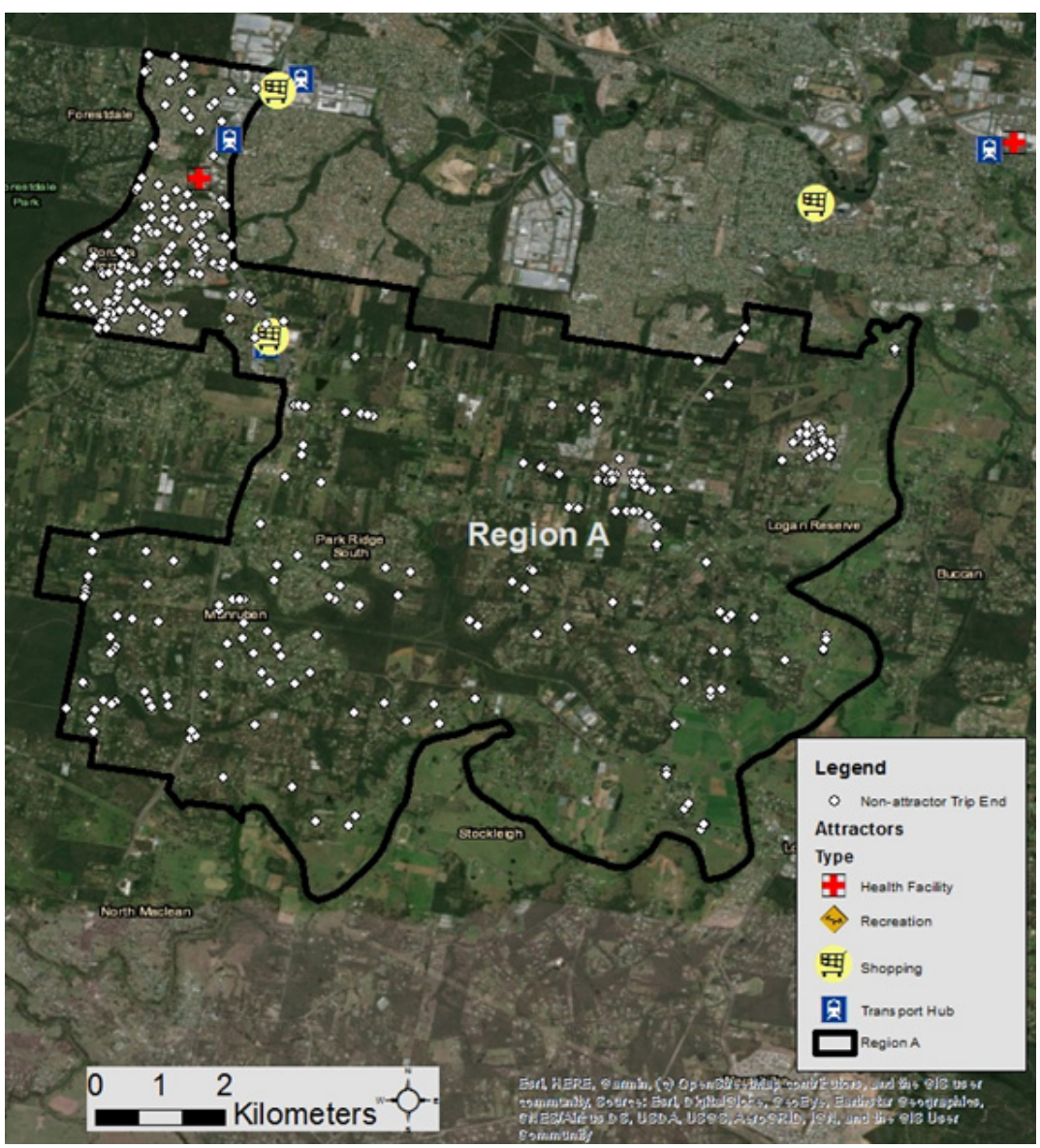

Figure 2. Map of Region A, DRT non-attractor trip ends (origins or destinations of trips that mostly represent users' homes) and attractors 
Region A consists of seven Logan suburbs and is the largest of the three regions covering $80.9 \mathrm{~km}^{2}$ It hosted a very dispersed population of 25,641 people with density of 317 people per $\mathrm{km}^{2}$ according to the 2016 Australian Census.

From within its area, residents can travel by DRT to 9 different attractors ( 4 transport hubs, 3 shopping centers, and 2 health facilities), some of which are outside of the designated service area. Region A had the most person trips of all three regions, with 50,669 trips made during the first 24 months of service. Average trip length was $13 \mathrm{~km}$, much higher than the in the other regions. In general, Region A is poorly served by FRT, with low frequency service during the week between 9 am and 5 pm on very few routes and without service in early morning or late evening.

\subsubsection{Region B: Mixed urban and suburban}

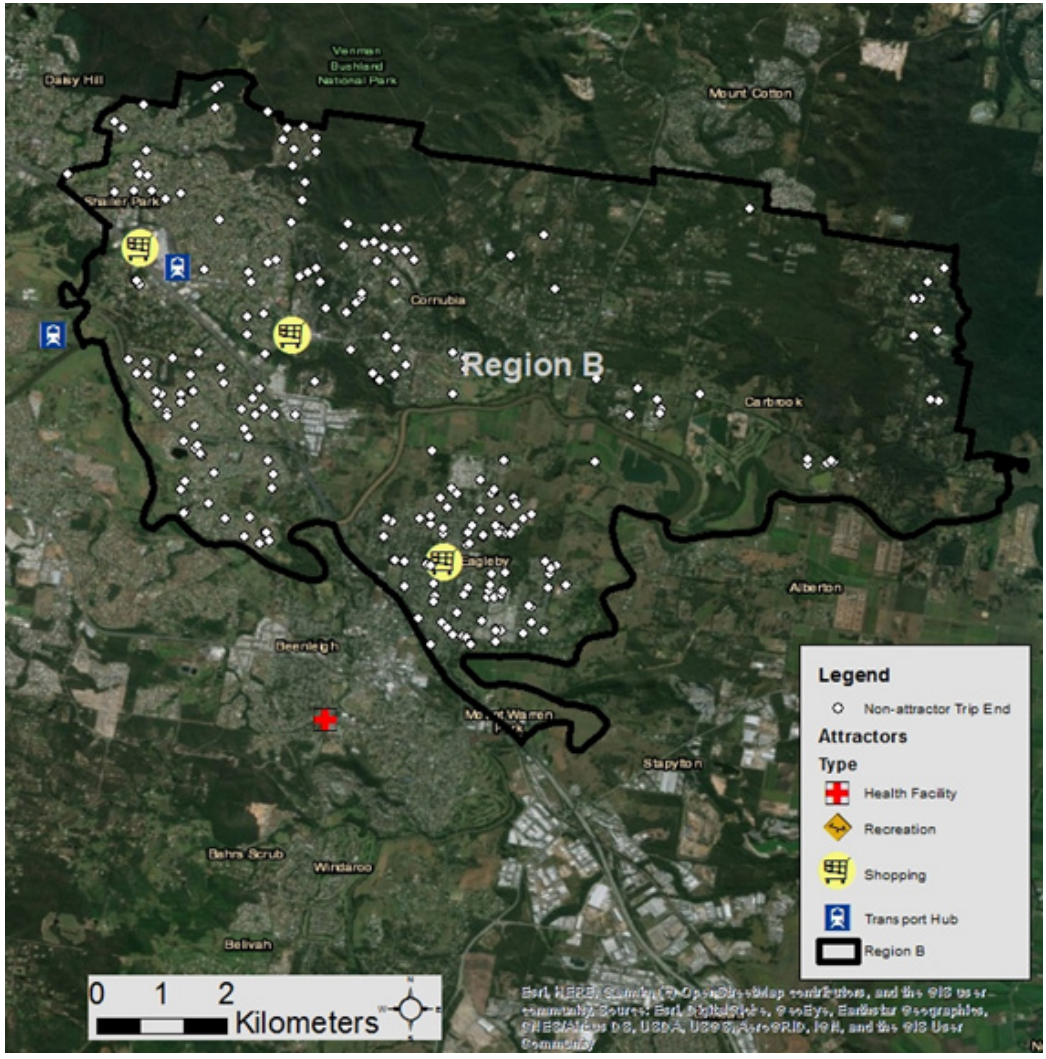

Figure 3. Region B and DRT non-attractor trip ends (origins or destinations of trips that mostly represent users' homes) and attractors

Region B covers 6 suburbs of Logan and is $69 \mathrm{~km}^{2}$ in area. It is mainly situated east of a major motorway and had a population of 44,496 in 2016. It has 2 main urban areas: Loganholme, with good public transport provision located in the northwest; and Eagleby with poor public transit service in the south. Overall, the region has a population density of 649 people per $\mathrm{km}^{2}$.

Residents in Region B can access 6 different attractors (3 shopping centers, 2 transport hubs, and 1 health facility). During the study period Region B had 31,370 trips, averaging only $5 \mathrm{~km}$ in length. Suburbs in Region B such as Eagleby are served by low frequency FRT services operating mainly between 9 am and 5 pm weekdays. 


\subsubsection{Region C: Urban}

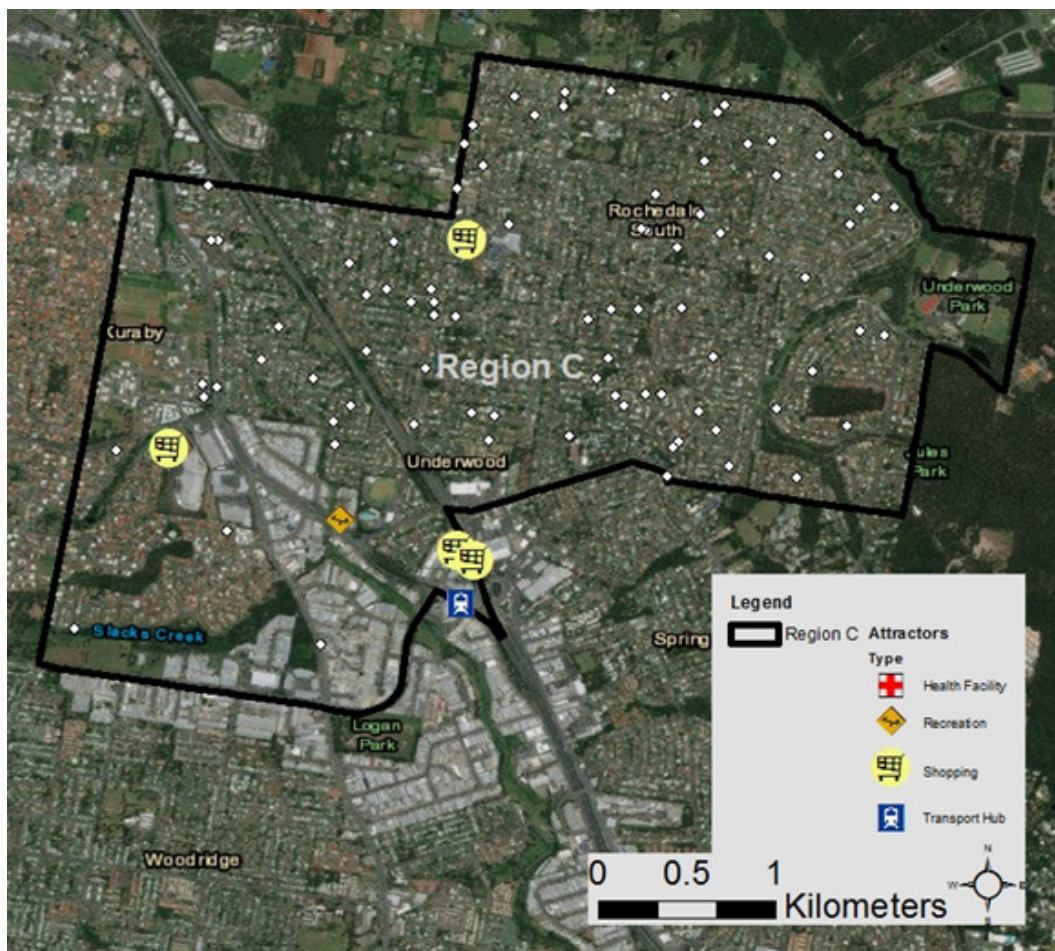

Figure 4. Region C DRT non-attractor trip ends (origins or destinations of trips that mostly represent users' homes) and attractors

Region $\mathrm{C}$ is the smallest and densest DRT trial region, covering two suburbs - Underwood and Rochedale South. With a population of 21,642 in 2016, it covers $9.6 \mathrm{~km}^{2}$ (density of $2,262 / \mathrm{km}^{2}$ ). The DRT service for Region $\mathrm{C}$ provides access to six attractors (3 shopping centers, 2 transport hubs, and 1 recreation center). Region $\mathrm{C}$ had the lowest total number of person trips since trial commencement $(5,194)$. These trips were short in length ( $4 \mathrm{~km}$ in average), which is unsurprising due to the small service area. Unlike the other regions, DRT trips are more dispersed across this region. Region C has a commuter train line running to the west of the service region, and some modest bus coverage, with a couple of low frequency routes operating through suburbs like Rochedale South from 6:30 am-7 pm on weekdays and with reduced hours on weekends. Though a high frequency service to the nearby South East Busway runs north through the service region from Springwood station in the south, there are no stops or stations for these services within Region C.

\section{$4 \quad$ Analysis and results}

Based on the overview of Logan's three service regions in Section 3.2, this section provides a more detailed comparison of the three regions using the derived metrics of DRT services outlined in Section 3.1. Do note, however, that cost data was not available for the three service regions and, as such, no cost metrics are included in this comparison. 


\subsection{Service region comparisons}

Table 2a summarizes the descriptive statistics of the three service regions. Region A may have substantially less population than Region B, but it has triple the average monthly trips made by DRT. Region A has the most unique customers, the most trips and the longest trips of all three regions. Contrary to theory, average monthly trips per service area are negatively associated with population density across the three regions.

Table $2 \mathrm{~b}$ provides a number of the derived metrics for the three service regions, as developed above. The demand density measure, which has been commonly used in previous DRT assessments, shows that Region A remains best performing. But despite having very few average monthly trips, Region $\mathrm{C}$ performs better on demand density than Region B. As area is the denominator, this metric favors smaller service region areas, which operators also prefer due to lower average trip lengths. Yet when we compare the population density adjusted trip rate a very different picture emerges. Region A performs extremely strongly on this metric, Region C extremely poorly. Despite having less than conducive land-use intensity, Region $\mathrm{A}$ is attracting much more demand than either of its comparator regions. Something else is strongly affecting patronage.

Table 2a. Descriptive statistics of Logan DRT service regions, July-September 2019

\begin{tabular}{|l|r|r|r|r|r|r|r|}
\hline $\begin{array}{c}\text { Service } \\
\text { Regions }\end{array}$ & $\begin{array}{c}\text { Population } \\
(2016)\end{array}$ & \multicolumn{1}{c|}{$\begin{array}{c}\text { Area } \\
\left(\mathrm{km}^{2}\right)\end{array}$} & $\begin{array}{c}\text { Population } \\
\text { Density }\end{array}$ & \multicolumn{1}{c|}{$\begin{array}{c}\text { Unique } \\
\text { customers }\end{array}$} & $\begin{array}{c}\text { Average trip } \\
\text { length }(\mathrm{km})\end{array}$ & $\begin{array}{c}\text { Designated } \\
\text { attractors }\end{array}$ & $\begin{array}{c}\text { Average } \\
\text { monthly trips }\end{array}$ \\
\hline Region A & 25,641 & 80.9 & 317 & 1,481 & 13 & 9 & 2,995 \\
\hline Region B & 44,496 & 68.6 & 649 & 552 & 5 & 6 & 897 \\
\hline Region C & 21,642 & 9.6 & 2,262 & 185 & 4 & 7 & 185 \\
\hline
\end{tabular}

Table 2b. Derived metrics of Logan DRT service regions, July-September 2019

\begin{tabular}{|l|r|r|r|r|}
\hline \multicolumn{1}{|c|}{ Service } & $\begin{array}{c}\text { Proportion of } \\
\text { population are unique } \\
\text { customers }\end{array}$ & \multicolumn{1}{|c|}{$\begin{array}{c}\text { Monthly trips per } \\
\text { population }\end{array}$} & Demand Density & $\begin{array}{c}\text { Population density } \\
\text { adjusted trip rate }\end{array}$ \\
\hline Region A & $5.78 \%$ & 0.12 & 37.02 & 9.45 \\
\hline Region B & $1.24 \%$ & 0.02 & 13.08 & 1.38 \\
\hline Region C & $0.85 \%$ & 0.01 & 19.27 & 0.08 \\
\hline
\end{tabular}

Table 3 shows the two measures of overlap between the FRT services and DRT for the three service regions. For the proportion of region within $400 \mathrm{~m}$ of a FRT stop, Region A is the least covered by FRT, with only $5.8 \mathrm{~km}^{2}(7 \%)$ of its area within $400 \mathrm{~m}$ of a bus stop or rail station. Region B has slightly more overlap at $18 \%$. Region $\mathrm{C}$ has considerable overlap (58\%). This result is strongly co-related with population density; the densest service regions have the most FRT provision.

Table 3. DRT/FRT overlap metrics

\begin{tabular}{|l|r|r|}
\hline & Proportion of region within 400m of FRT stop & $\begin{array}{l}\text { Proportion of non-attractor DRT trips located } \\
\text { within 400m of FRT stop }\end{array}$ \\
\hline Region A & $7 \%$ & $32 \%$ \\
\hline Region B & $18 \%$ & $28 \%$ \\
\hline Region C & $58 \%$ & $67 \%$ \\
\hline
\end{tabular}


The percentages all increase for each region when considering the proportion of non-attractor DRT trips located within $400 \mathrm{~m}$ of a FRT stop. In Region A, some $32 \%$ of such trips are made within $400 \mathrm{~m}$ of a FRT stop. In Region C it's 67\%. Trip-makers living within easy walking distance of the FRT stops are, on average, more likely to use DRT than those living further away. This hints that DRT is potentially being used as a supplement to other transit services, though this would need to be confirmed by other data sources.

\subsection{A caveat - the modifiable aerial unit problem (MAUP)}

The above measures were calculated using each service region as the unit of analysis. Spatial analysis with the use of administrative boundaries is inevitably affected by how they were delineated - this is known as the modifiable aerial unit problem (MAUP) (Openshaw \& Taylor, 1979). While overall Region A was the region with highest utilization of DRT, subsequent disaggregate analysis using different geographies revealed a more nuanced picture.

The effects of MAUP were tested by bisecting Region A into two discrete sub-regions, as shown in Figure 5. A higher-density sub-region A1 was identified covering mostly the suburb of Boronia Heights in the north-west of the service region. This sub-region has a much higher population density $(1,682$ people $\left./ \mathrm{km}^{2}\right)$ than the region as a whole $\left(317\right.$ people $\left./ \mathrm{km}^{2}\right)$. Sub-region A1 (high density) hosts multiple attractors, as well as many shopping and employment opportunities, and has most of Region A's bus services. Sub-region A1 is somewhat similar to Region C in land use, with a population density of 158 people per $\mathrm{km}^{2}$ Sub-region A2, the remainder, covers an extremely low-density area that is mostly acreage, farms, and a few scattered housing developments. A major arterial road separates the two subregions, a "natural" barrier separating land-use patterns.

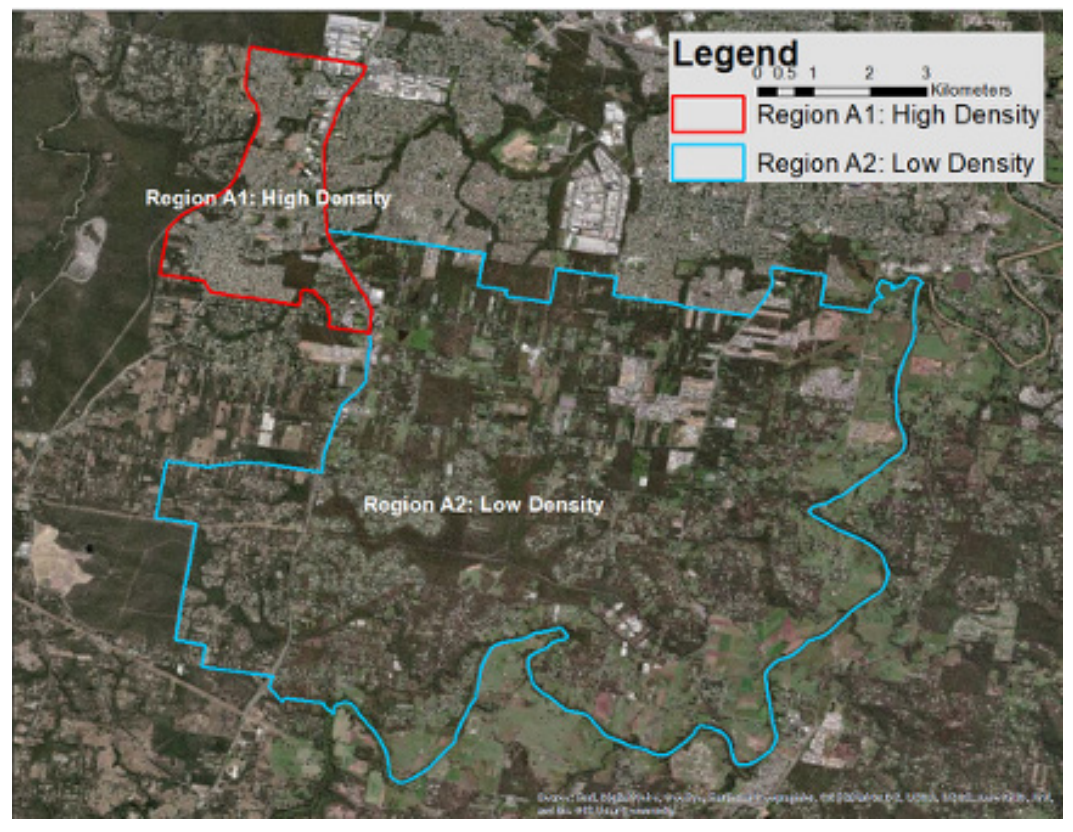

Figure 5. Subdivision of Region A into two sub-regions 
Tables $4 \mathrm{a}$ and $4 \mathrm{~b}$ show the results of the disaggregate analysis, revealing how choice of scale can mask variability across geographies. As Table 4 a shows, despite having a lower population, sub-region A2 has 152\% more average monthly trips than sub-region A1.

Table 4a. Sub-regional analysis of Region A

\begin{tabular}{|l|r|r|r|r|r|r|r|r|}
\hline Subregion & $\begin{array}{c}\text { Population } \\
(2016)\end{array}$ & $\begin{array}{c}\text { Area } \\
\left(\mathrm{km}^{2}\right)\end{array}$ & $\begin{array}{c}\text { Population } \\
\text { Density }\end{array}$ & $\begin{array}{c}\text { Average } \\
\text { monthly trips } \\
\text { since service } \\
\text { commencement }\end{array}$ & $\begin{array}{c}\text { Monthly } \\
\text { trips per } \\
\text { population }\end{array}$ & $\begin{array}{c}\text { Demand } \\
\text { Density }\end{array}$ & $\begin{array}{c}\text { Population } \\
\text { density } \\
\text { adjusted } \\
\text { trip rate }\end{array}$ & $\begin{array}{c}\text { Aver- } \\
\text { age Trip } \\
\text { Length } \\
\text { (km) }\end{array}$ \\
\hline $\begin{array}{l}\text { A1 -High } \\
\text { density }\end{array}$ & 14,091 & 8 & 1,682 & 600 & 0.04 & 71.43 & 0.36 & 8.78 \\
\hline $\begin{array}{l}\text { A2 - Low } \\
\text { density }\end{array}$ & 11,550 & 73 & 158 & 1512 & 0.13 & 20.68 & 9.57 & 12.21 \\
\hline $\begin{array}{l}\text { Region A } \\
\text { (Overall) }\end{array}$ & 25,641 & 81 & 317 & 2,111 & 0.08 & 26.09 & 6.66 & 10.90 \\
\hline
\end{tabular}

Table 4b. DRT/FRT overlap metrics

\begin{tabular}{|l|r|r|}
\hline \multicolumn{1}{|c|}{ Sub-region } & $\begin{array}{r}\text { Proportion of region within 400m of } \\
\text { FRT stop }\left(\mathrm{km}^{2}\right)\end{array}$ & $\begin{array}{r}\text { Proportion of non-attractor DRT trips } \\
\text { located within 400m of FRT stop }\end{array}$ \\
\hline A1 - High density & $\mathbf{4 8 . 1 1 \%}$ & $\mathbf{8 0 . 3 0 \%}$ \\
\hline A2 - Low density & $\mathbf{2 . 4 2 \%}$ & $\mathbf{0 . 6 1 \%}$ \\
\hline Region A (Overall) & $\mathbf{7 . 1 2} \%$ & $\mathbf{3 1 . 0 1 \%}$ \\
\hline
\end{tabular}

The derived metrics demonstrate major differences between the two sub-regions and the effect of MAUP. Sub-region A1 performs better in terms of the population density adjusted trip rate (9.57 vs. 0.36 in A2) but with lower demand density (20.68 vs. 71.43). Two alternative readings of the overlap comparison and the trip distance data might explain further why sub-region A1 out-performs on the population density adjusted trip rate. Table $4 \mathrm{~b}$ shows that most residents in sub-region A2 effectively have no other public transit available to them. But they tend to use the DRT services more than the residents in A1 who have significant FRT supply. This is contrary to the effects seen in the aggregated analysis performed on all three regions. Further, the greater average DRT trip distances in sub-region A2 might also help explain the appeal of the DRT system there. With a low flat-fare, residents in A2 get a much better deal per $\mathrm{km}$ travelled by DRT, than those in A1, which may attract more passengers to the service.

\section{$5 \quad$ Discussion and concluding remarks}

In this paper, we discussed the most common set of DRT evaluation metrics, proposed alternative metrics, and tested them across multiple regions that provide a "natural experiment" for cross-service comparison. The main contributions of this paper to the field of transport and land-use planning can be classified as conceptual, methodological and practical. While this research was tailored to specifically examine a DRT service across three Australian suburban regions in the same local government area, the concepts and methods are transferable, and the results show new possibilities for DRT service evaluation. The novel density-based trip rate metric provided here proved especially powerful in the Logan analysis. It provides a simple, easy-to-understand metric with low data requirements to compare DRT 
services to each other, determining high and low efficiency whilst controlling for density and land-use intensity. These new metrics rely on data sources that are widely available in many jurisdictions, allowing widespread application. They also have potential for application with not just DRT, but also FRT and other new modes of public mobility, such as bikesharing and e-scooter sharing. Most importantly, they could help open up a new suite of inter-system DRT comparisons, even across sub-national (e.g., State/Province) or national borders. With most DRT data being increasingly standardized with new agreements on GTFS for DRT (MacDonald, 2020) there is increasing potential for comparisons to understand the effects of a range of factors on system performance, and learn from leading implementers.

Our proposed population density adjusted trip rate metric could be useful, in part, for estimating the overall spatial equity of DRT services in a region, though capturing data on who is using DRT services would be necessary to get a true picture of equity impacts, especially from a Rawlsian perspective where one is trying to provide for the least-advantaged in society. Our metrics may help identify fixed routes that could better serve the public by shifting to partial or fully demand responsive deployments (Mulley \& Nelson, 2009). In planning new DRT service areas, forecasted trip rates alone may not justify services - population density and urban form matter as well. Using demand density metrics alone, the Logan sub-region A2 looks poor. On population density adjusted trip rate, A2 performs well. Without being able to see the nuances, sub-optimal decisions could be taken. Our metrics therefore help inform decision-makers to understand how systems are performing. But they have their limitations.

In terms of theory, the dilemma of trade-offs between efficiency and equity in transit provision (Walker, 2011) is in part revealed by our results. Demand density is an apt metric to evaluate service efficiency; population density adjusted trip rates reflect the accessibility benefits for lower density areas. It is likely these measures are inversely correlated, leading to an important theoretical discussion of who DRT should serve. In theory, there are two key types of users and service aims:

Group 1. Captive users, such as the mobility impaired (e.g., those with no cars) or disabled who should be served, even if the costs are high, as a matter equity and meeting basic human needs.

Group 2. Non-captive (or choice) users, such as existing car users. If DRT becomes popular enough to enjoy economies of scale, then it should be considered amongst other options for transport supply. At the least, it should be balanced with social benefits (e.g., reduced environment costs or health benefits from incidental exercise). However, provision of large-scale subsidies for suburban and peri-urban residents may reinforce low-density living - a contentious topic.

That debate will vex decision-makers with scarce transport funds. But identifying passenger types for each system is a key goal to help make good choices. The data available in Logan does include some parameters that could potentially allocate passengers to Group 1 or 2 . But for many passengers it is not always obvious that they are captive users. Additional data sources may be needed. Capturing more systematic de-identifiable data on system users, via their registration, across systems, in similar ways to the national rail passenger surveys used in many countries, could further help the DRT research effort.

We envisage the primary beneficiaries of this research are communities with sprawling development patterns, such as where the majority of DRT deployments are found in North America and Australia. Finally, as demonstrated across Logan's regions and sub-regions, our results further confirm that the "one-size-fits-all" approach for DRT service may not be the best. There are significant inter-region and intra-regional differences that warrant adjustment to service patterns. While standardized services 
are easier to tender for and are often a good political "sell" to the public, they can be sub-optimal. In future, transit planners, funding organizations, operators, and technology providers should make reference to urban land uses and trip patterns when planning and evaluating DRT and FRT systems, and design these systems accordingly.

\subsection{Limitations}

There are several limitations of this study. To better evaluate and justify DRT services, extended analyses with consideration of socio-demographics such as income and level of disadvantage are required. Nevertheless, our current method and proposed metrics serve as a baseline for such extensions.

Firstly, as demonstrated in the analysis in section 4.2, comparison using these metrics is highly dependent on the design of the service region, resulting in a MAUP. To minimize this, smaller census geographies should be considered as the basic unit of study (Leung, Burke, \& Cui, 2018). Another approach is to use randomly assigned grids (e.g., $1 \times 1 \mathrm{~km}$ squares, or hexagons) to address this problem (Nazari Adli, Chowdhury, \& Shiftan, 2019). Due to the high granularity data inputs required for smaller spatial units, this approach was not used in this paper. More DRT trip data may be needed for such analyses.

Secondly, our Logan analysis did not allow for cost-based evaluation, a sensitive topic with any funding agency. In our view, some cost-based metrics are blind to the social equity benefits that DRT provides, areas often more costly to serve. We acknowledge this is a limitation - as the ability to demonstrate value to riders per cost subsidy is important in political decisions of DRT funding. Ideally, ways will be found in which DRT costs can be disaggregated into service regions, and there will be standardization in the ways in which costs are generally reported. Perhaps a combined tool that integrates costs alongside the metrics we have proposed might help explore the dilemma of cost-effectiveness and equity concerns in DRT provision. But this may prove difficult to achieve. Failures to standardize and share cost data will limit the types of cross-service comparisons possible in future. We call for regulators to mandate better data retention and sharing requirements, and likewise DRT operators should also step up data collection for more the development of nuanced insight and tools which may benefit research and to provide better services.

\subsection{Future research opportunities}

As DRT continues to grow and technology improves, further improvement to the set of available evaluation metrics will be necessary but such also requires better data collection, as this paper is hamstrung by this limitation. As a way forward, a list of suggested future metrics that should be developed are presented below in Table 5 . 
Table 5. Suggested future evaluation metrics

\begin{tabular}{|l|l|l|}
\hline Future DRT Metric & Basic data requirements & Advanced data requirements \\
\hline Equitable coverage impacts & Geospatial coverage data & $\begin{array}{l}\text { Socio-economic census data for newly } \\
\text { covered regions, dependent on variables of } \\
\text { interest. Rider demographic data. }\end{array}$ \\
\hline Access to employment & Geospatial coverage data & $\begin{array}{l}\text { Employment density data, trip purpose } \\
\text { evaluation, and local transit network data. }\end{array}$ \\
\hline Vehicle occupancy rate & Trip rate & $\begin{array}{l}\text { Per trip occupancy rate for DRT fleet. } \\
\text { Multiple rider booking rate and ride- } \\
\text { matching rate. }\end{array}$ \\
\hline Average hypothecated cost per trip & Cost per trip data & $\begin{array}{l}\text { Trip length projections, vehicle occupancy } \\
\text { rates }\end{array}$ \\
\hline $\begin{array}{l}\text { Frequency or hours-of-service related } \\
\text { FRT overlap metrics }\end{array}$ & GTSF data, geospatial coverage data & $\begin{array}{l}\text { Transit stop, hours of operation and/or } \\
\text { headway data; street/path network data }\end{array}$ \\
\hline Time-specific demand and supply & Trips requested and fulfilled & $\begin{array}{l}\text { Time-stamped DRT service calls and } \\
\text { service provided with demographic data, } \\
\text { traffic data for cross comparison }\end{array}$ \\
\hline
\end{tabular}

Evaluation of transit service redundancy would be improved by using either frequency, hours-ofoperation, or combined metrics. This can be calculated for most DRT regions worldwide using publicly available GTFS data and DRT coverage files. This is the next logical step for improving FRT/DRT overlap metrics. Breaking down the hours-of-operation data (such as morning/afternoon/evening) would especially help to reveal the percentage changes, and also demand/supply changes during different times of day. This data is not commonly available, and we call for transport operators to better collect or share this data to researchers.

\subsubsection{Equitable coverage impacts}

The lack of equity impact evaluation and demographic data used to evaluate service deployment and uptake demonstrates a clear future avenue of research.

Those with low rates of car ownership, low socio-economic status, high proportion of minorities, and elderly populations have been shown to have higher levels of DRT adoption than the general public (Jain, Ronald, Thompson, \& Winter, 2017; Nelson \& Phonphitakchai, 2012; Wang, Quddus, Enoch, Ryley, \& Davison, 2015; Yang \& Cherry, 2017). In some instances, access to jobs has been a key initiator of DRT services (Social Exclusion Unit, 2003; Wright, Nelson, Cooper, \& Murphy, 2009). More elaborate methods may be developed to explore DRT service impacts on these particular groups, but there will be limits on how much cross-system evaluation will be possible given the paucity of disaggregate data available. Such methods might better allow DRT services covering large cohorts of these groups but experiencing low ridership to be re-evaluated for potential service adjustment. This could include adjusting the service region, the choice of attractors/destinations, the fare structure, or, potentially, full replacement with an alternative transit option.

The impacts of these services on riders in these disadvantaged categories should not be missed. Use of census data coupled with ridership data related to transport equity would enhance understanding of uptake of services by certain groups. Collection of rider data can be easily completed during signup but is more difficult to collect later on using rider surveys. Such data were not included in this study and represent an opportunity to expand the current work.

Whether and how commuting trips are linked by DRT is an important consideration of the usefulness of DRT services. Employment locations could be considered in DRT assessment. As the Logan 
DRT service was designed to provide households with access to key activity nodes, not direct services to key employment centers (e.g., Brisbane CBD) focusing on employment was not a priority in our case study. However, other DRT services have been deployed as commuter services, warranting specialized analyses to evaluate their performance. This offers a future area of specialized research as DRT typologies become more solidified and consistent.

DRT operates under the concept of sharing rides between users to increase occupancy rates in vehicles and reduce individual costs. An increase in sharing will increase the efficiency of services, especially in high demand areas. Average occupancy rate and frequency of shared rides are directly related to operational metrics such as allowed route deviation. Low occupancy rates can be improved by increasing leniency in pickup and drop off times and locations, or by offering cost savings for those sharing rides. However, ride-sharing rates may contradict goals of servicing low density communities where there are fewer opportunities to share rides, such as in Logan. Without inclusion of sharing metrics in our evaluation protocol, it is impossible to determine best practices that enhance sharing of rides. However, long-term this will be very important for improving the longevity of services.

While a rather simplistic method is used in the paper, the advantage is it is easy to apply across systems. We have also demonstrated a wide range of derivatives that can be produced even with monthly data. Should higher temporal and spatial resolution data be available, we could also offer grid maps with different DRT demand and supply - which could even help identify use patterns and demand for better service. Better data collection and sharing will benefit future researchers in producing more nuanced insights. As demonstrated in our work, the field of DRT needs to form a strong foundation of metrics specific to its operational needs and should not just rely on those created for other forms of transit. Doing so will ensure that new DRT services expand transit coverage, are planned effectively, and provide better service to those that they intend to serve. The proposed metrics in this paper is a start to unifying the complex interrelationships of DRT uptake (demand and supply) and urban form (as reflected by population density). This provides a strong foundation on which to build future metrics that take on important yet more complicated issues such as service efficiency and equity.

\section{Acknowledgements}

The authors would like to thank the Queensland Department of Transport and Main Roads through the Transport Academic Partnership for their support. Specific thanks to Alec Tattersall, Erika Jolley, and Gary Wood for their valuable input and feedback throughout the analysis formation. Additional thanks to the editors and reviewers whose time and efforts have improved the quality of this research. 


\section{References}

Alonso-González, M. J., Liu, T., Cats, O., van Oort, N., \& Hoogendoorn, S. (2018). The potential of demand-responsive transport as a complement to public transport: An assessment framework and an empirical evaluation. Transportation Research Record: Journal of the Transportation Research Board, 2672(8), 879-889. http://doi.10.1177/0361198118790842

Behbahani, H., Nazari, S., Jafari Kang, M., \& Litman, T. (2018). A conceptual framework to formulate transportation network design problem considering social equity criteria. Transportation Research Part A: Policy and Practice, 125, 171-183. http://doi.10.1016/j.tra.2018.04.005

Bertolaccini, K., \& Lownes, N. (2013). Effects of scale and boundary selection in assessing equity of transit supply distribution. Transportation Research Record, 58-64. http://doi.10.3141/2350-07

Brake, J., Mulley, C., \& Nelson, J. D. (2006). Good practice guide for demand responsive transport services using telematics. Newcastle upon Tyne, UK: Newcastle University.

Brake, J., Nelson, J. D., \& Wright, S. (2004). Demand responsive transport: Towards the emergence of a new market segment. Journal of Transport Geography, 12(4), 323־337. http://doi.10.1016/j. jtrangeo.2004.08.011

Burge, M. (2017, July 11). Demand responsive transport: Coming to an outer metropolitan suburb near you. Jimboomba Times (Jimboomba, Australia). https://www.jimboombatimes.com.au/story/4784275/the-future-of-public-transport-is-demanding-video/

Burke, M., \& Brown, L. (2007). Distances people walk for transport. Road \& Transport Research: A Journal of Australian and New Zealand Research and Practice, 16(3), 15-29.

Eboli, L., \& Mazzulla, G. (2012). Performance indcators for and objective measure of public transport service quality. European Transport, 51, 1-21.

Enoch, M., Potter, S., Parkhurst, G., \& Smith, M. (2004). INTERMODE: Innovations in demand responsive transport. London: Department of Transport.

Enoch, M., Potter, S., Parkhurst, G., \& Smith, M. (2006). Why do demand responsive transport systems fail? Paper presented at the 85th Annual Meeting of the TRB, Washington, DC.

Ferreira, L., Charles, P., \& Tether, C. (2007). Evaluating flexible transport solutions. Transportation Planning and Technology, 30(2-3), 249-269. http://doi.10.1080/03081060701395501

Hansen, W. G. (1959). How accessibility shapes land use. Journal of the American Institute of Planners, 25(2), 73-76. http://doi.10.1080/01944365908978307

Heramb, C., Sen, A., \& Soot, S. (1979). Jitney paratransit services: An appraisal of present and future operations. Washington, DC: Transportation Research Board

Hine, J. (2011). Mobility and transport disadvantage. In M. Grieco \& J. Urry (Eds.) Mobilities: New perspectives on transport and society (pp. 21-39). Farnham, UK: Ashgate Publishing.

Ho, S. C., Szeto, W. Y., Kuo, Y.-H., Leung, J. M. Y., Petering, M., \& Tou, T. W. H. (2018). A survey of dial-a-ride problems: Literature review and recent developments. Transportation Research Part B: Methodological, 111, 395-421. http://doi.10.1016/j.trb.2018.02.001

Holoszyc, M. (1979). Dial-a-ride in Rochester: Search for a viable suburban transit alternative. Paper presented at the Annual Meeting of the Transportation Research Board, Washington, DC.

Infrastructure Australia. (2018). Outer urban public transport: Improving accessibility in lower-density areas. Retrieved from https://www.infrastructureaustralia.gov.au/publications/outer-urban-publictransport-improving-accessibility-lower-density-areas

Jain, S., Ronald, N., Thompson, R., \& Winter, S. (2017). Predicting susceptibility to use demand responsive transport using demographic and trip characteristics of the population. Travel Behavior and Society, 6, 44-56. http://doi.10.1016/j.tbs.2016.06.001

Kim, M., Schonfeld, P., \& Kim, E. (2018). Switching service types for multi-region bus systems. Trans- 
portation Planning and Technology, 41(6), 617-643. http://doi.10.1080/03081060.2018.1488930

Leung, A., Burke, M., \& Cui, J. (2018). The tale of two (very different) cities-Mapping the urban transport oil vulnerability of Brisbane and Hong Kong. Transportation Research Part D: Transport and Environment, 65, 796-816. http://doi.10.1016/j.trd.2017.10.011

Li, X., \& Quadrifoglio, L. (2010). Feeder transit services: Choosing between fixed and demand responsive policy. Transportation Research Part C: Emerging Technologies, 18(5), 770-780. http:// doi.10.1016/j.trc.2009.05.015

Litman, T. (2013). The new transportation planning paradigm. Institute of Transportation Engineers Journal, 83(6), 20-27.

Logan City Council. (2018). Statistics and facts. Retrieved from https://www.logan.qld.gov.au/aboutlogan/living-in-logan/statistics-and-facts

Lucas, K. (2012). Transport and social exclusion: Where are we now? Transport Policy, 20, 105-113. http://doi.10.1016/j.tranpol.2012.01.013

Lucas, K., Phillips, I., Mulley, C., \& Ma, L. (2018). Is transport poverty socially or environmentally driven? Comparing the travel behaviors of two low-income populations living in central and peripheral locations in the same city. Transportation Research Part A: Policy and Practice, 116, 622-634. http://doi.10.1016/j.tra.2018.07.007

MacDonald, R. (2020). Mobility on demand (MOD) sandbox: Vermont Agency of Transportation (VTrans) flexible trip planner. Barre, VT: Vermont Agency of Transportation.

Martens, K. (2006). Basing transport planning on principles of social justice. Berkeley Planning Journal, 19, $1-17$.

Morse, L., Trompet, M., Barron, A., \& Graham, D. J. (2017). Development of a key performance indicator system to benchmark relative paratransit performance. Transportation Research Record: Journal of the Transportation Research Board, 2650(1), 1-8. http://doi.10.3141/2650-01

Mulley, C., \& Nelson, J. D. (2009). Flexible transport services: A new market opportunity for public transport. Research in Transportation Economics, 25(1), 39-45. http://doi.10.1016/j.retrec.2009.08.008

Narayan, J., Cats, O., van Oort, N., \& Hoogendoorn, S. P. (2020). Fleet size determination for a mixed private and pooled on-demand system with elastic demand. Transportmetrica A: Transport Science. http://doi.10.1080/23249935.2020.1819910

National Academy of Sciences, Engineering, and Medicine. (2008). Guidebook for measuring, assessing, and improving performance of demand-response transportation. Washington DC: The National Academies Press.

Nazari Adli, S., Chowdhury, S., \& Shiftan, Y. (2019). Justice in public transport systems: A comparative study of Auckland, Brisbane, Perth and Vancouver. Cities, 90, 88-99. http://doi.10.1016/j. cities.2019.01.031

Nelson, J. D., \& Phonphitakchai, T. (2012). An evaluation of the user characteristics of an open access DRT service. Research in Transportation Economics, 34(1), 54-65. http://doi.10.1016/j.retrec.2011.12.008

Openshaw, S., \& Taylor, P. (1979). A million or so correlation coefficients: Three experiments on the modifiable areal unit problem. In Statistical applications in the spatial sciences (pp. 127-144). London: Wrigley N. Publishers.

Oxley, P. (2007). Dial/a/ride: A review. Transportation Planning and Technology, 6(3), 141-148. http:// doi.10.1080/03081068008717184

Papanikolaoua, A., Basbasa, S., Mintsisa, G., \& Taxiltaris, C. (2017). A methodological framework for assessing the success of demand responsive transport (DRT) services. Paper presented at the 3rd Conference on Sustainable Urban Mobility, Volos, Greece. 
Perera, S., Ho, C., \& Hensher, D. (2019). Resurgence of demand responsive transit services - Insights from BRIDJ trials in inner west of Sydney, Australia. Retrieved from https://ses.library.usyd.edu.au/ handle/2123/21283

Rawls, J. (1971). A theory of justice. Cambridge, MA: Belknap Press, Harvard.

Reinhardt, L. B., Clausen, T., \& Pisinger, D. (2013). Synchronized dial-a-ride transportation of disabled passengers at airports. European Journal of Operational Research, 225(1), 106-117. http:// doi.10.1016/j.ejor.2012.09.008

Ryley, T. J., Stanley, P. A., Enoch, M. P., Zanni, A. M., \& Quddus, M. A. (2014). Investigating the contribution of demand responsive transport to a sustainable local public transport system. Research in Transportation Economics, 48, 364-372. http://doi.10.1016/j.retrec.2014.09.064

Sen, A. (2009). The idea of justice. Westminster, England: Penguin Books Limited.

Social Exclusion Unit. (2003). Making the connections: Final report on transport and social exclusion. Melbourne, Australia: Social Research In Transport Clearinghouse, Monash University.

Stiglic, M., Agatz, N., Savelsbergh, M., \& Gradisar, M. (2015). The benefits of meeting points in ridesharing systems. Transportation Research Part B-Methodological, 82, 36-53. http://doi.10.1016/j. trb.2015.07.025

Te Brömmelstroet, M., \& Bertolini, L. (2009). Integrating land use and transport knowledge in strategy-making. Transportation, 37(1), 85-104. http://doi.10.1007/s11116-009-9221-0

Translink. (2017). Demand responsive transport community consultation report. Brisbane, Australia: Translink.

Translink. (2019). Demand responsive transport trials. Retrieved from https://translink.com.au/travelwith-us/drt

Walker, J. (2011). Human transit: How clearer thinking about public transit can enrich our communities and our lives. Washington, DC: Island Press.

Wang, C., Quddus, M., Enoch, M., Ryley, T., \& Davison, L. (2015). Exploring the propensity to travel by demand responsive transport in the rural area of Lincolnshire in England. Case Studies on Transport Policy, 3(2), 129-136. http://doi.10.1016/j.cstp.2014.12.006

White, P. (2016). The roles of 'conventional' and demand-responsive bus services. Transport and Sustainability, 8, 307-330. http://doi.10.1108/s2044-994120160000008015

Wright, S., Nelson, J. D., Cooper, J. M., \& Murphy, S. (2009). An evaluation of the transport to employment (T2E) scheme in Highland Scotland using social return on investment (SROI). Journal of Transport Geography, 17(6), 457-467. http://doi.10.1016/j.jtrangeo.2008.10.006

Yang, H., \& Cherry, C. (2017). Use characteristics and demographics of rural transit riders: A case study in Tennessee. Transportation Planning and Technology, 40(2), 213-227. http://doi.10.1080/030810 60.2016.1266168

Zheng, Y., Li, W., \& Qiu, F. (2018). A methodology for choosing between route deviation and point deviation policies for flexible transit services. Journal of Advanced Transportation. http:// doi.10.1155/2018/6292410 